Article

\title{
Comparative Analysis of Child Restraint Systems Safety Parameters in Relation to the New Regulation No. 129 of the Economic Commission for Europe of the United Nations (UN/ECE)
}

\author{
Artur Muszyński *, Jakub Łuszczek and Rafał Szymaniuk \\ IDAP Technology Ltd. Jagiellonska 55 St. 03-301 Warsaw, Poland; jakub.luszczek@idap.com.pl (J.Ł.); \\ rafal.szymaniuk@idap.com.pl (R.S.) \\ * Correspondence: artur.muszynski@idap.com.pl
}

Received: 8 January 2020; Accepted: 20 February 2020; Published: 24 February 2020

\begin{abstract}
This study presents a comparison of the common Child Restraint Systems (CRS) which reduces the value of dynamic loads affecting the child's body during car accidents. The analyzed systems were: child seats, booster seats, and straps—adjustable vehicle seat belts adapted to children's stature. The effectiveness of the analyzed devices was assessed on the basis of experimental tests carried out in the accredited laboratory approving the Child Restraint Systems. The tests were carried out in accordance with the new Regulation No. 129 UN/ECE. The authors examined whether the tested devices meet the guidelines of the new Regulations No. 129 despite approval in accordance with Regulation No. 44. Based on the research results, better safety parameters of some new solutions dedicated to children's safety could be observed. Almost all the selected CRS met requirements stated in Regulation No. 129. The only exception was for abdominal pressure in one of the tested devices. Head Resultant Acceleration in tested devices was 14.7-39.0\% less than the limit determined in Regulation No. 129 whereas Chest Resultant Acceleration was 17.4-37.6\% less. Abdominal pressure was $46.4-81.4 \%$ beneath the limit (apart from one case which did not meet the requirements). The HPC parameter (Head Performance Criterion) was $45.4-74.5 \%$ less. The final results show that there are still some possibilities for improving the safety of young vehicle passengers.
\end{abstract}

Keywords: child seats; car accidents; car crash analyses; children safety

\section{Introduction}

Based on the World Health Organization's available research results, every year, children die or are seriously injured during car crashes on roads in all over the world [1-3]. To reduce the enormous number of children's deaths and injuries in car crashes, researchers from R\&D departments in commercial companies and scientists from scientific facilities are developing different technologies to increase children's safety in vehicles [4-8]. Additionally, there is available research connected with innovative materials and technologies which could be used in CRS systems [9-13]. A significant number of children are saved by airbags, seat belts in child seats, car seat belts connected with Child Restraint Systems CRS [7] in all cars and additional devices for passive protection. All these elements can absorb part of the energy during an impact $[14,15]$. Despite all the available solutions for children's safety during car crashes, the Economic Commission for Europe of the United Nations (UN/ECE) is still working to improve the approval requirements to increase children's safety during car crashes. All of the devices for children's safety available in the market have to assure the dynamic load's reduction during a car collision. According to the dynamic load's reduction requirement, there are several main parameters that are measured during every test. To obtain approval, the value of each 
parameter must be below a strict limit. In the new Regulation No. 129 of the Economic Commission for Europe of the United Nations (UN/ECE), the following parameters are registered: acceleration of the test trolley, force in the dummy's neck, movement in the dummy's neck, thoracic acceleration in three directions, displacement in the chest of the dummy, left and right abdominal pressure [16]. All the sensors mentioned are necessary to detect as many variables as possible to avoid children's bodies being injured during a car collision. According to the comparison of the previous and new UN regulation, Child Restraint Systems should have different parameters to fulfill the main requirements in each regulation. During the analysis in this study, it was taken into account how newly included parameters affect potential body damage during a car crash influence the examination results.

The main purpose of the research conducted by the authors of this paper was to analyze the common devices of Child Restraint Systems, including child seats, booster seats, and straps adjusting vehicle seat belts to children's sizes. All test results were compared and shown in specially prepared charts to determine how the common solutions for children's safety meet the new requirements.

\section{Experimental}

Frontal collision simulation tests for Child Restraint Systems were carried out in an accredited test unit authorized to carry the tests out according to the guidelines of UN/ECE Regulation No. 129. The tests were focused on determining the impact of the dynamic loads acting on the child's body transported in five child restraint systems. It was also determined how measured parameters meet the new guidelines of the No. 129 Regulations. Each CRS was mounted on a test bench, then accelerated to receive appropriate speed and then, decelerated, which is a crucial parameter of this research, which was shown in Figure 1. Every test for the particular device was carried out with the same initial conditions so that the research was comparable and reliable. After the tests, the results of each CRS were compared in terms of sensitive points on a child's body as specified in the regulation. Prepared dummies in CRS system are shown in figures in Table 1.

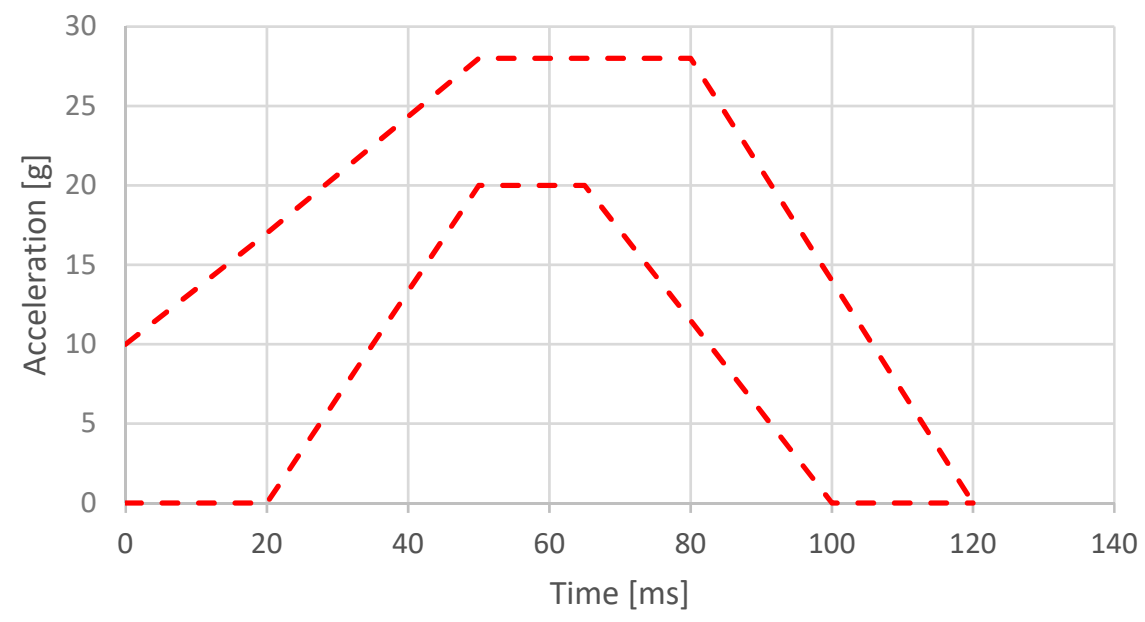

Figure 1. Description of the acceleration curve of the test trolley. For frontal impact, the trolley was propelled so that at the beginning of the test, its velocity was $50(+0 /-2) \mathrm{km} / \mathrm{h}$ and its acceleration curve was within the hatched area. 
Table 1. Child Restraint Systems (CRS) systems before crashtests.

CRS Type Dummy in CRS Photo
$\begin{gathered}\text { Smart Kid Belt (Smart KID S.A.; } \\ \text { Borzęcin Mały; Poland) }\end{gathered}$

Britax Römer Kid II (BRITAX RÖMER

Kindersicherheit $\mathrm{GmbH}$; Leipheim; Germany)

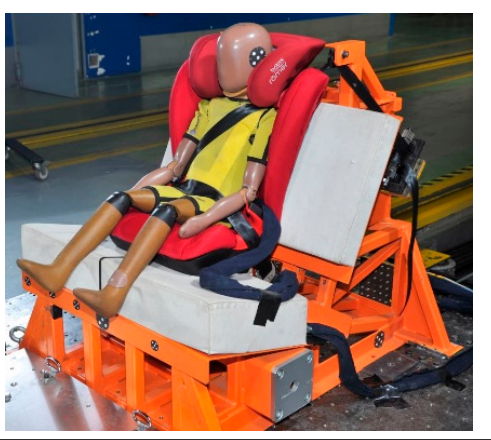

Combi Booster Seat (Combi Hong Kong Limited; Hong Kong; China)

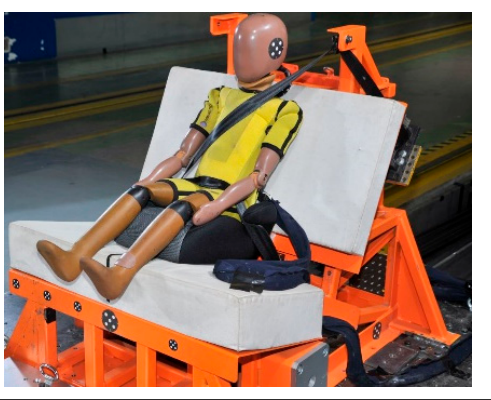

Combi Joy Trip Egg Shock (Combi Hong Kong Limited; Hong Kong; China)

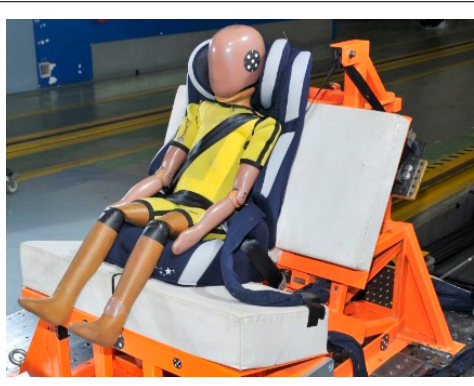

Concord Transformer X (CONCORD 2004 S.A.; Barcelona; Spain)

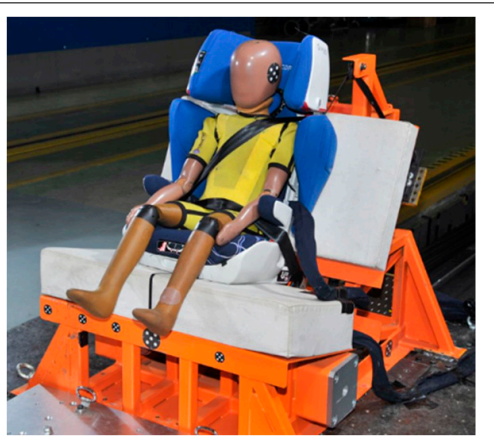


The tested devices were mounted on the specially prepared test seat for the approval process prepared according to Annex 6 ECE 129. The requirement of a seat cushion and the test bench being supported from a square foam block was subjected. For frontal impact, the trolley was propelled so that during the test, its total velocity change $\Delta V$ was $52(+0 /-2) \mathrm{km} / \mathrm{h}$ and its acceleration curve was within the hatched area of the graph in Annex 7, Appendix 1 and stayed above the segment defined by the coordinates $(5 \mathrm{~g}, 10 \mathrm{~ms})$ and $(9 \mathrm{~g}, 20 \mathrm{~ms})$. The start of impact $\left(\mathrm{T}_{0}\right)$ is defined, according to ISO 17373 standard for a level of acceleration of $0.5 \mathrm{~g}$. To achieve the most research credibility, the tests were carried out on the same day under the same temperature conditions. All five devices for the tests were delivered 48 hours before the planned tests and were stored at the Institute in a specially prepared air-conditioned room. During the tests, the image from the collision was recorded using two high-speed cameras and the acceleration and forces measured on the dummy in selected parts of its body. For the tests, the anthropomorphic dummy Q6 series was used (corresponding to children under the age of six).

The sensors were registered with the following parameters:

- the test trolley's acceleration,

- the dummy's head acceleration, where the maximum value may not exceed $80 \mathrm{~g}$ for the Q6 head cumulative 3 ms value,

- the dummy's chest acceleration, where the maximum value may not exceed $55 \mathrm{~g}$ for the Q6 chest cumulative 3 ms value,

- the forces and bending moment in the upper part of the cervical spine,

- the deflection of the dummy torso,

- the pressure in the left and right abdominal sections of the dummy.

\section{Results}

For all the devices tested, the data are shown in line charts. For additional visualization, all characteristic values are compared in bar charts.

The first chart (Figure 2) shows Chest Resultant Acceleration which aims to determine how the acceleration changes with time. It allows to compare how a particular device works-delay of initiation of action - that is why each peak is displaced from the other. There are two accumulations of peaks; the first one is considered because of the impact that occurs-rapid deceleration of the test bench. They are the highest peaks that give information about accelerations in the child's body.

For the Smart Kid Belt and for the Britax Römer Kid II, an earlier delay increasing as a function of time can be observed. The nature of this phenomenon is associated with the shorter time of the clearance elimination between the child's dummy and the seat belts, i.e., the dummy begins to slow down together with the test trolley. It can also be observed that the maximum recorded delays for the Britax Römer Kid II are smaller than in the Smart Kid Belt. This could be connected with the construction features of each restraint system. The highest acceleration value was in the Combi Booster Seat and Combi Joy Trip Egg Schock.

The comparison of the limit of acceleration pointed in Regulation No. 129 was made with the actual results obtained from the test. The final results are shown in the bar chart (Figure 3)-they are a ratio between test results and the Chest Resultant Acceleration specified in the Regulation (55 g), which determines the safety parameters of the particular Child Restraint System as a percentage. 


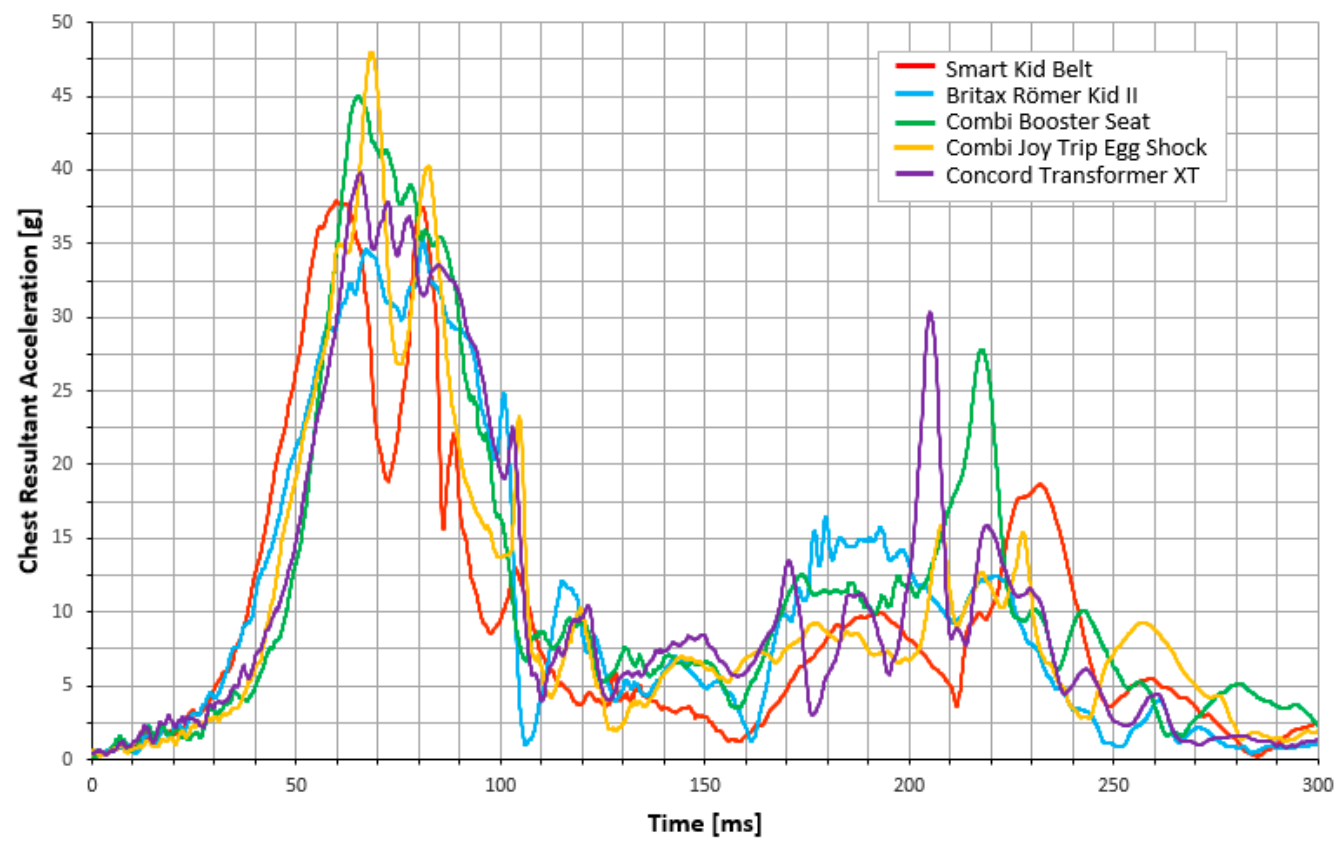

Figure 2. Chest Resultant Acceleration for all CRS tested as a function of time. The graph shows how the chest acceleration changes with time- the first, highest peaks provide information about the maximum chest acceleration during the rapid deceleration of the test bench.

- Smart Kid Belt

Britax Römer Kid II

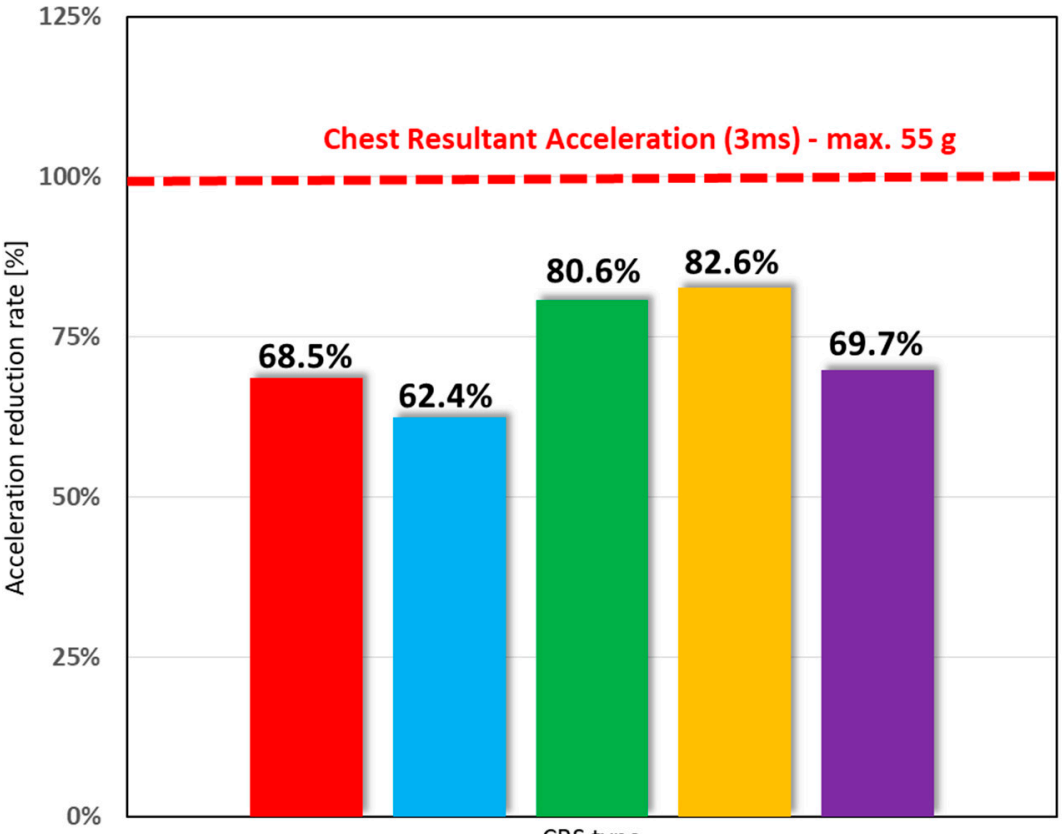

Concord

- Transformer X

CRS type

Figure 3. Chest Resultant Acceleration for all CRS tested regarding the maximum limit according to Reg. No. 129. The best result was Britax Romer Kid II-37.6\% beneath the limit. The worst one among the other CRS was the Combi Joy Trip Egg Shock.

The maximum recorded chest delay values for the devices tested are:

- for the Smart Kid Belt: $37.85 \mathrm{~g}$ in $59.2 \mathrm{~ms}$,

- for the Britax Römer Kid II: $35.14 \mathrm{~g}$ in $80.3 \mathrm{~ms}$,

- for the Combi Booster Seat: $45.02 \mathrm{~g}$ in $64.2 \mathrm{~ms}$, 
- $\quad$ for the Combi Joy Trip Egg Shock: 48.21 in $67.7 \mathrm{ms,}$

- $\quad$ for the Concord Transformer X: $39.75 \mathrm{~g}$ in $64.9 \mathrm{~ms}$.

One of the approval criteria according to regulation No. $129 \mathrm{UN} / \mathrm{ECE}$ is the reduction of torso acceleration with a value greater than or equal to $55 \mathrm{~g}$ for cumulative $3 \mathrm{~ms}$ values. During the analysis of data from the acceleration measurement in five different constructions, it can be observed that the characteristic values were not exceeded in any of the Child Restraint Systems. For individual restraint devices, the maximum values recorded of chest acceleration for cumulative 3 ms values were:

- for the Smart Kid Belt: $37.69 \mathrm{~g}$ for the time interval between 58.5 and $80 \mathrm{~ms}$, where it is $68.5 \%$ of the limit,

- for the Britax Römer Kid II: $34.33 \mathrm{~g}$ for the time interval between 65.8 and $81 \mathrm{~ms}$, where it is $62.4 \%$ of the limit,

- for the Combi Booster Seat: $44.37 \mathrm{~g}$ for the time interval between 63 and $66 \mathrm{~ms}$, where it is $80.6 \%$ of the limit,

- for the Combi Joy Trip Egg Shock: $45.44 \mathrm{~g}$ for the time interval between 66.2 and $69.2 \mathrm{~ms}$, where it is $82.6 \%$ of the limit,

- for the Concord Transformer X: $38.35 \mathrm{~g}$ for the time interval between 63.1 and $66.1 \mathrm{~ms}$, where it is $69.7 \%$ of the limit.

For the Smart Kid Belt, the fastest increase in dummy's head delay value as a function of time (Figure 4) was recorded. Acceleration increasing for the strap device appears at least $8 \mathrm{~ms}$ earlier than the other tested solutions. Due to construction differences between the tested solutions, the acceleration in the torso for the Britax Römer Kid II does not correspond with the increase of the acceleration in the head (this also applies to the maximum values of the registered acceleration). During the analysis of the kinematics of the child dummy movement, it can be observed that the boundary conditions within the initial position of the dummy (including angles between the torso and head, torso with lower limbs) and the characteristics of the element on which the dummy is directly located are different. All the construction characteristics mentioned, shown in Figure 5 could have a significant impact on the recorded values.

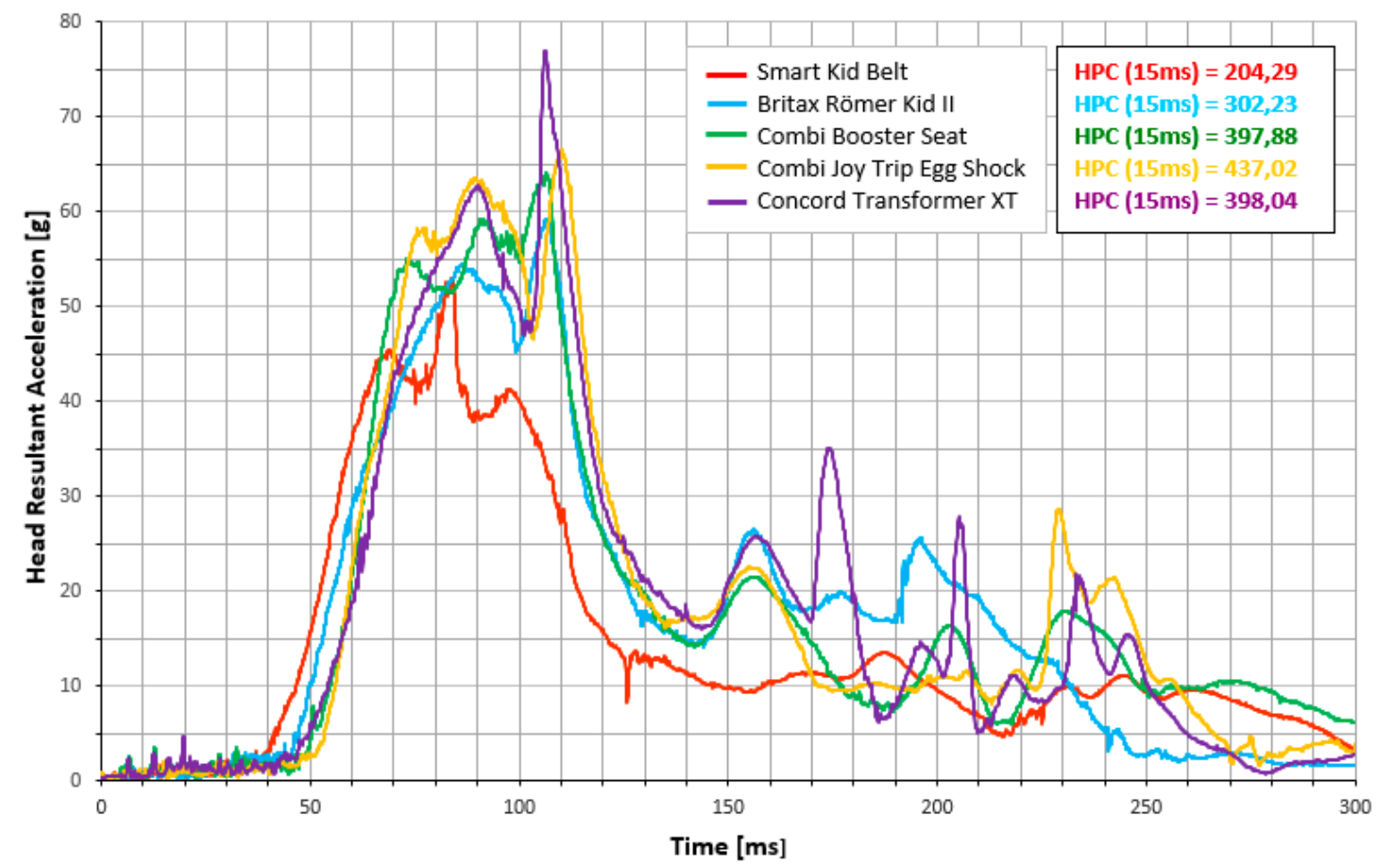

Figure 4. Head Resultant Acceleration for all tested devices. 


Smart Kid Belt
Britax Römer Kid II
Combi Booster
Seat
Combi Joy Trip
Egg Shock
Concord
Transformer $\mathrm{X}$

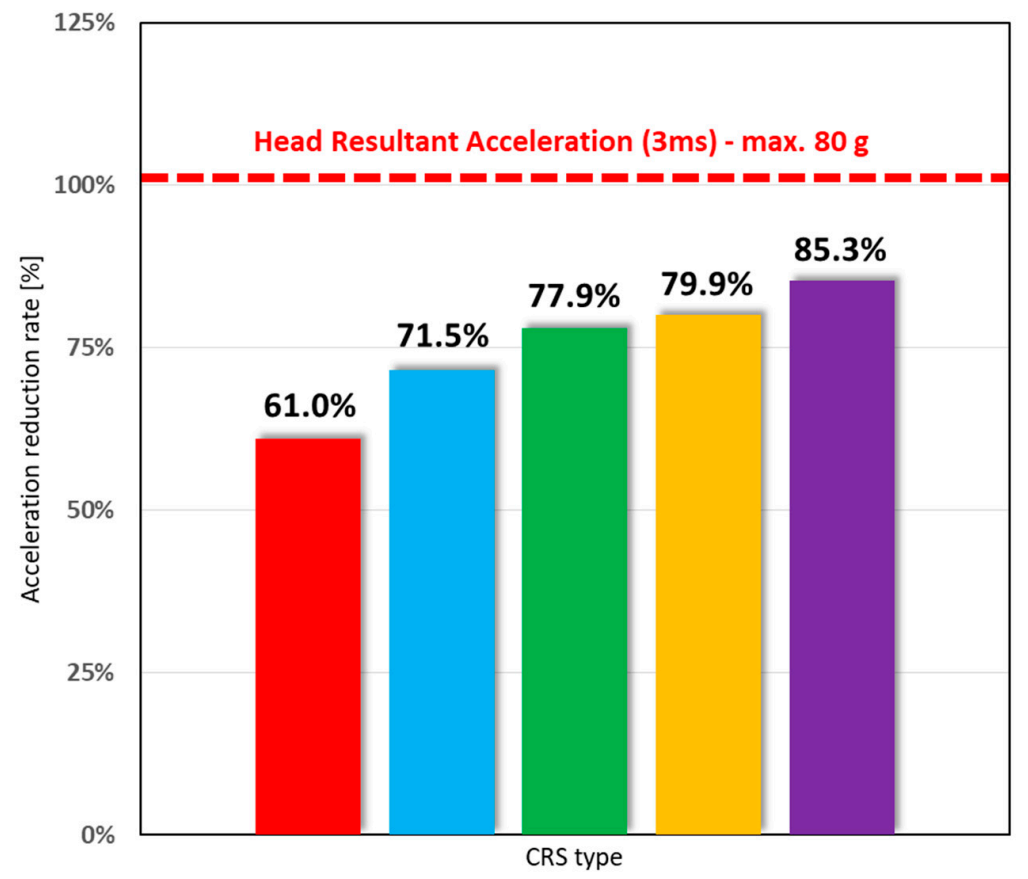

Figure 5. Head Resultant Acceleration for all the tested devices regarding the maximum limit. Smart Kid Belt was the safest device-39\% beneath the $80 \mathrm{~g}$. Concord Transformer X was the least safe CRS but still did not exceed the limit (14,7\%).

The maximum recorded acceleration values of individual devices are:

- $\quad$ for the Smart Kid Belt: $52.97 \mathrm{~g}$ at $83.7 \mathrm{~ms}$

- for the Britax Römer Kid II is: $59.25 \mathrm{~g}$ at $106.2 \mathrm{~ms}$.

- for the Combi Booster Seat: $64.26 \mathrm{~g}$ at $106.3 \mathrm{~ms}$,

- for the Combi Joy Trip Egg Shock: $66.55 \mathrm{~g}$ at $109.4 \mathrm{ms,}$

- $\quad$ for the Concord Transformer X: $77.01 \mathrm{~g}$ at $106 \mathrm{~ms}$.

One of the approval criteria according to No. 129 UN/ECE regulation is the reduction of the accelerations in the head with a value greater than or equal to $80 \mathrm{~g}$ for cumulative $3 \mathrm{~ms}$ values. Analyzing data from the accelerations in the head of the test dummy in five different constructions, it can be observed that all the values were not exceeded in any of the restraint systems tested. The maximum recorded values of head acceleration cumulative $3 \mathrm{~ms}$ values for each device are as follows:

- for the Smart Kid Belt: $48.83 \mathrm{~g}$ for the time interval between 81.5 and $84.5 \mathrm{~ms}$, where it is $61.0 \%$ of the limit,

- for the Britax Römer Kid II: $57.23 \mathrm{~g}$ for the time interval between 104.6 and $107.9 \mathrm{~ms}$, where it is $71.5 \%$ of the limit,

- for the Combi Booster Seat: 62.34g for the time interval between 104 and $107.2 \mathrm{~ms}$, where it is $77.9 \%$ of the limit,

- for the Combi Joy Trip Egg Shock: $63.97 \mathrm{~g}$ for the time interval between 108.2 and $111.3 \mathrm{~ms}$, where it is $79.9 \%$ of the limit,

- for the Concord Transformer X: $68.24 \mathrm{~g}$ for the time interval between 105.2 and $108.3 \mathrm{~ms}$, where it is $85.3 \%$ of the limit. 
The calculation of the value of Head Performance Criterion (HPC) is made on the basis of the dummy's head acceleration using the following Equation (1):

$$
H P C=\left(t_{2}-t_{1}\right)\left[\frac{1}{t_{2}-t_{1}} \int_{t_{1}}^{t_{2}} a d t\right]^{2.5}
$$

where

- $\quad a$ is the resultant acceleration is measured in units of gravity, $\mathrm{g}\left(1 \mathrm{~g}=9.81 \mathrm{~m} / \mathrm{s}^{2}\right)$;

- $t_{1}$ and $t_{2}$ are time instants, expressed in seconds, defining the time interval between the beginning and the end of the recording for which the value of HPC is maximum.

According to the No. 129 UN/ECE regulation, when Child Restraint Systems are tested in a complete vehicle or a vehicle body shell, the head performance criterion (HPC) and the Head Acceleration $3 \mathrm{~ms}$ shall be used as assessment criteria (Figure 6). Where there is no head contact, these criteria shall be passed without measurement and recorded only as "No Head Contact". For HPC research purposes, a value was calculated for a 15-ms time interval for all the Child Restraint Systems tested. The HPC is a biomechanical parameter described as the highest load value in a time interval which is not more than $15 \mathrm{~ms}$. It should be emphasized that the values included in many scientific studies are related to critical HPC parameter values. According to No. 129 UN/ECE regulation, the critical value of HPC15 is 800 for the Q6 dummy. Few scientific studies have shown a tendency to include additional parameters that are not related to the critical parameters but may have a significant impact on injuries generation during an accident. According to [16], the value of the Head Injury Criteria parameter for a ten-year-old child when this child could be injured is 400 . This is the main reason why it is necessary to take into account the situation in which the injury limit values may occur at much lower HPC parameter values.

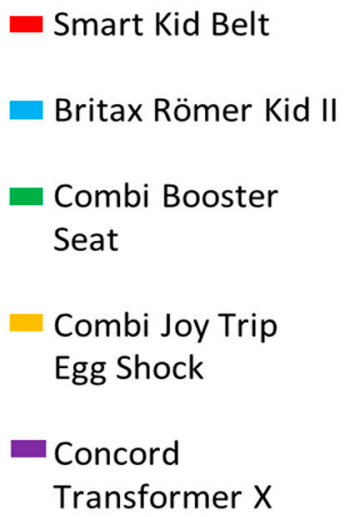

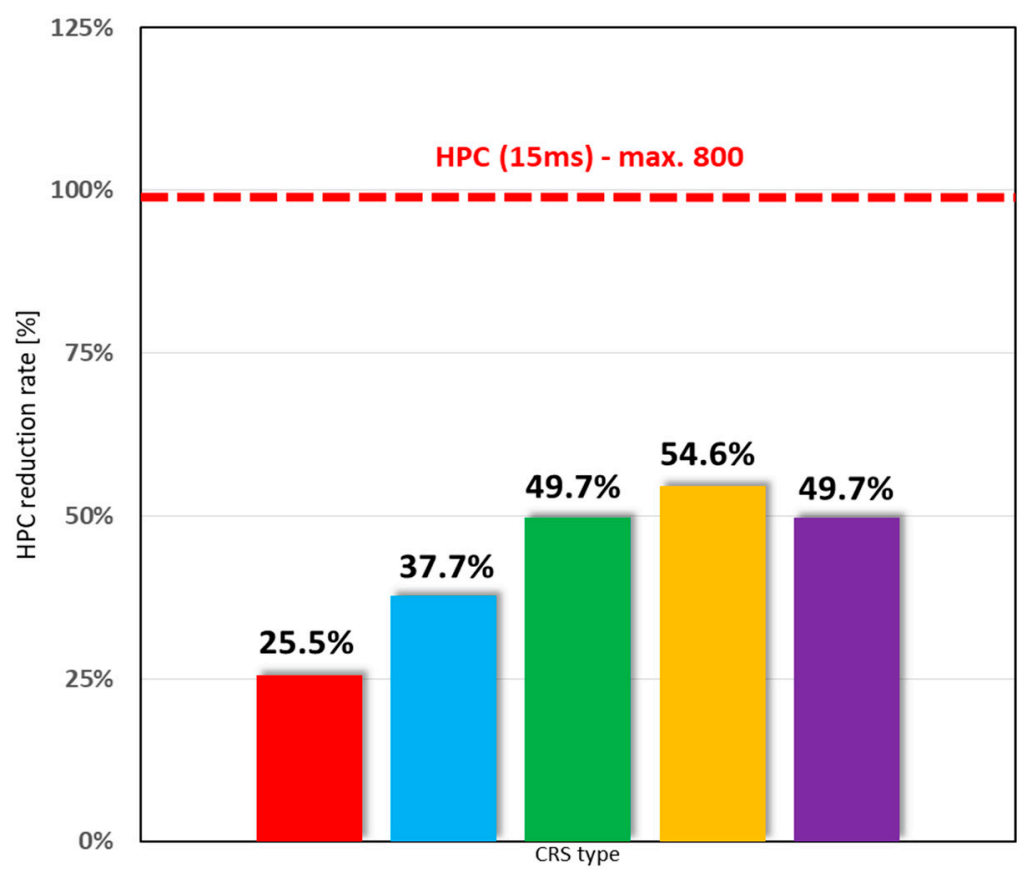

Figure 6. Head Performance Criterion for all tested devices regarding the maximum limit. Smart Kid Belt provided the best safety parameters $-25.5 \%$ of 800 is a very good result and about $50 \%$ less than Combi Joy Trip Egg Shock. 
The determined values of the biomechanical HPC parameter for individual devices are:

- for the Smart Kid Belt: HPC is 204.29 for the time interval between 70 and 85 ms, where it is $25.5 \%$ of the limit,

- for the Britax Römer Kid II: HPC is 302.23 for the time interval between 81 and 96 ms, where it is $37.7 \%$ of the limit,

- $\quad$ for the Combi Booster Seat: HPC is 397.88 for the time interval between 92.7 and 107.7 ms, where it is $49.7 \%$ of the limit,

- $\quad$ for the Combi Joy Trip Egg Shock: HPC is 437.02 for the time interval between 83.5 and $98.5 \mathrm{~ms}$, where it is $54.6 \%$ of the limit,

- $\quad$ for the Concord Transformer X: HPC is 398.04 for the time interval between 80.1 and $95.1 \mathrm{~ms}$, where it is $49.7 \%$ of the limit.

In connection to the No. $129 \mathrm{UN} / \mathrm{ECE}$ regulation, there are no legal guidelines regarding the limits of forces and moments values in the dummy's neck. Currently, these parameters are for monitoring purposes only. The registered forces (Figure 7) and moments in the dummy's neck segment are very important parameters due to the direct impact on the biomechanical features of the child's body. The head of a 9 -month-old baby represents $25 \%$ of its total body weight. For comparison, the head of an adult male is only $6 \%$ of his weight. Head injuries in children are often very serious because their skulls are significantly different in structure from those of adults. The newborn cervical vertebrae are made up of separate bone parts connected by cartilage. The children's ossification process continues until puberty. At the same time, gradually, muscle and cervical tendons develop. In addition, human cervical vertebrae change their shapes over the years in the process of growth. This phenomenon is the main reason for the totally different biomechanical characterization of children's bodies in comparison to adults. The most significant difference is a disproportionately large and heavy head, which affects the reduction body strength of a child during a car collision.

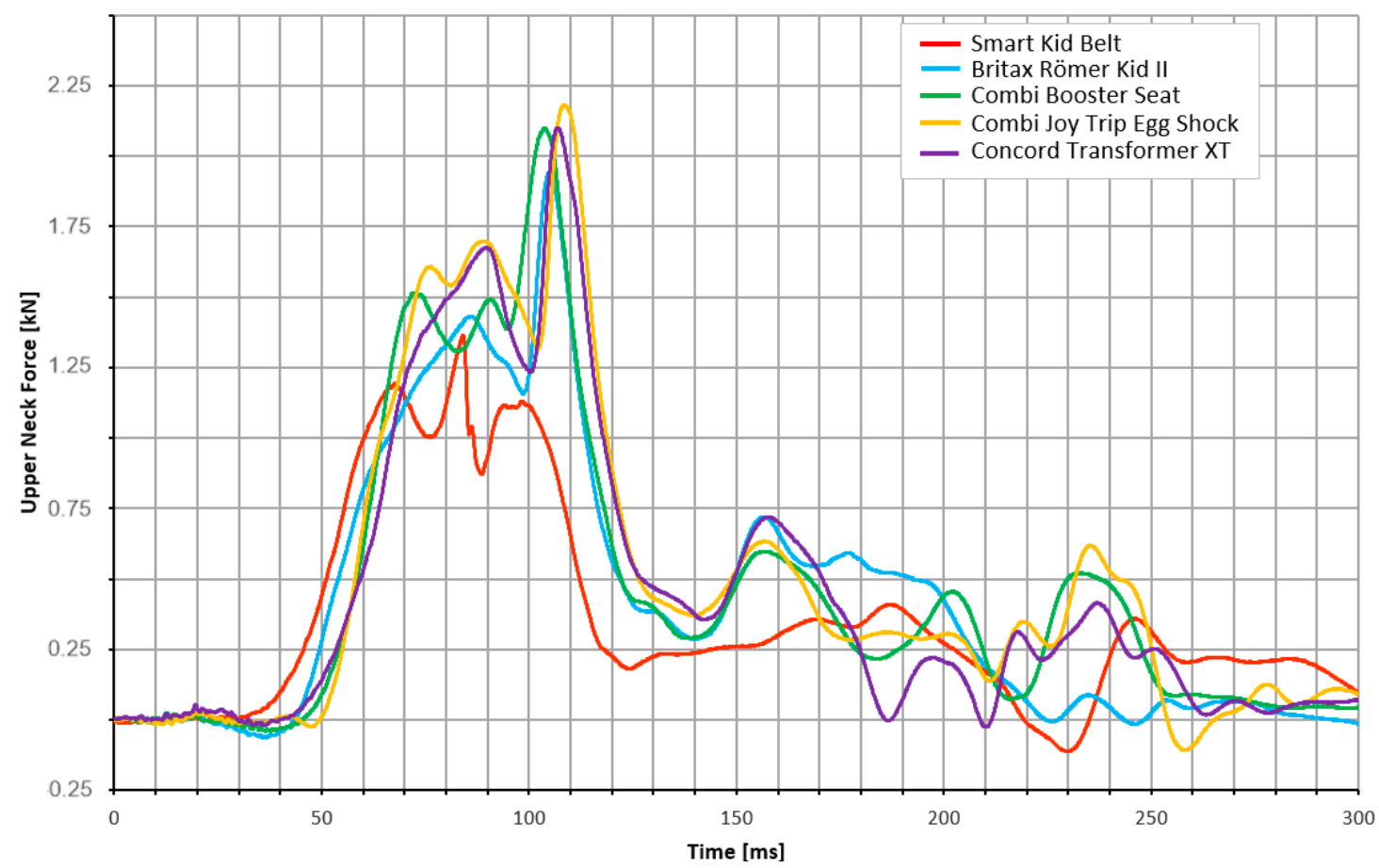

Figure 7. Upper neck force for all the devices tested. The graph shows how the upper neck force changes with time - the first, highest peaks provide information about maximum neck force during rapid deceleration of the test bench. 
The maximum registered value of neck tension force and neck bending moment for individual devices are:

- $\quad$ for the Smart Kid Belt: $1364.31 \mathrm{~N}$ during $84.1 \mathrm{~ms}$ and $53.15 \mathrm{Nm}$ during $94.1 \mathrm{~ms}$.

- for the Britax Römer Kid II: $1941.41 \mathrm{~N}$ during 104.9 ms and $55.56 \mathrm{Nm}$ during 104.9 ms.

- $\quad$ for the Combi Booster Seat: 2097.25 N during 103.7 ms and $60.19 \mathrm{Nm}$ during $103 \mathrm{~ms}$.

- $\quad$ for the Combi Joy Trip Egg Shock: 2182.21N during 108.4 ms and 56.57 Nm during $108.1 \mathrm{~ms}$.

- for the Concord Transformer X: $2099.58 \mathrm{~N}$ during $106.9 \mathrm{~ms}$ and $53.41 \mathrm{Nm}$ during $106.3 \mathrm{~ms}$.

The torso deflection value, shown in Figure 8, according to the regulations is currently for monitoring purposes only. Analyzing the test results, it can be stated that the maximum recorded torso deflection value for individual devices are:

- for the Smart Kid Belt: $-16.49 \mathrm{~mm}$ after $99.8 \mathrm{~ms}$.

- for the Britax Römer Kid II: -28.93 mm after 107 ms,

- for the Combi Booster Seat: $-26.2 \mathrm{~mm}$ after $106.2 \mathrm{~ms}$,

- for the Combi Joy Trip Egg Shock: $-33.76 \mathrm{~mm}$ after $110.5 \mathrm{~ms}$,

- for the Concord Transformer X: -27.94 mm after $110 \mathrm{~ms}$.

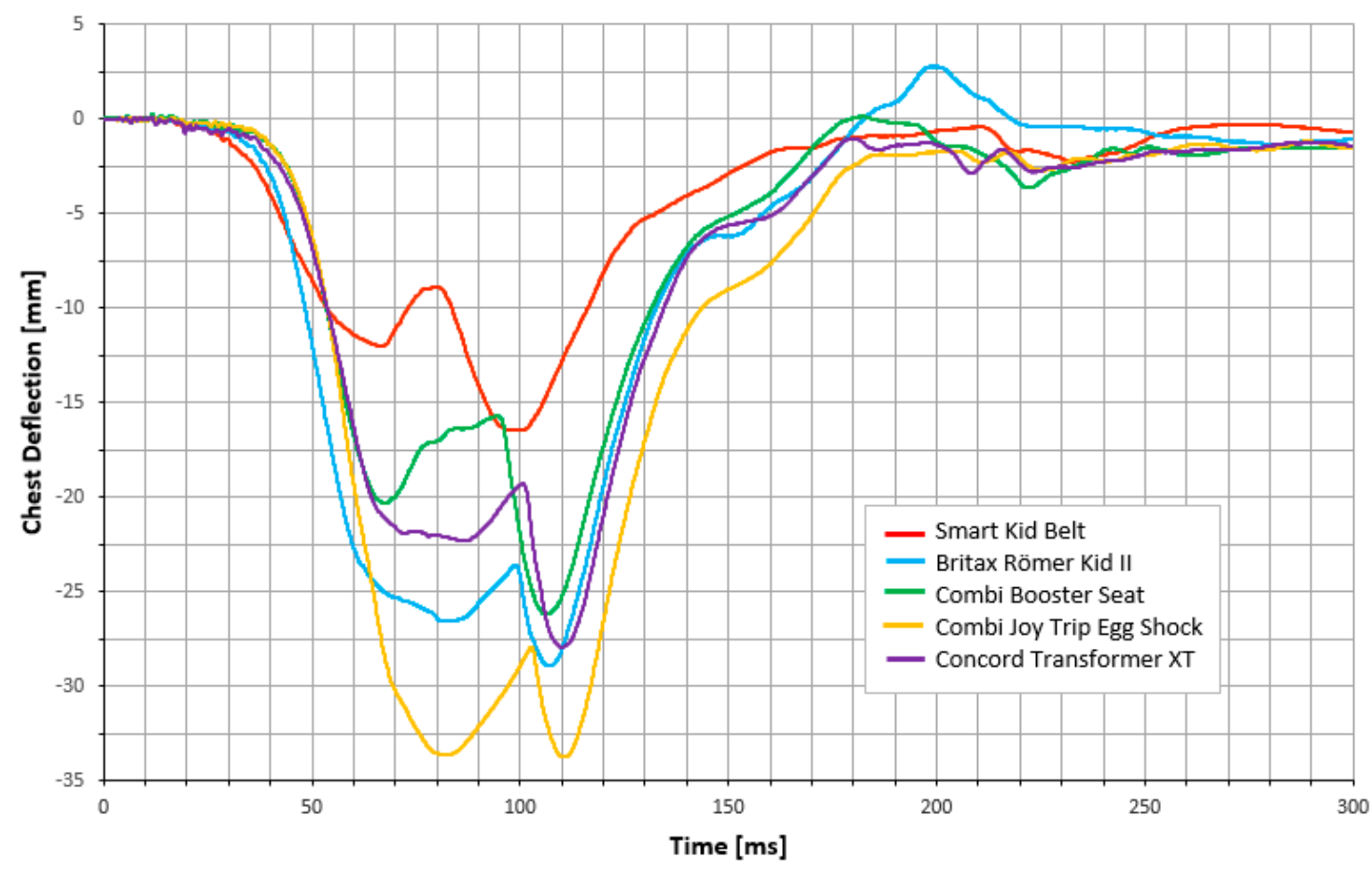

Figure 8. Chest deflection for all tested devices. The graph shows how the chest deflection changes with time- the highest peaks provide information about maximum chest deflection during rapid deceleration of the test bench.

According to the No. $129 \mathrm{UN} / \mathrm{ECE}$ regulation, the highest recorded value of abdominal pressure (Figure 9) is applicable for injury assessment. For the proper measurement selection, the higher pressure value from both sides is taken into account. 


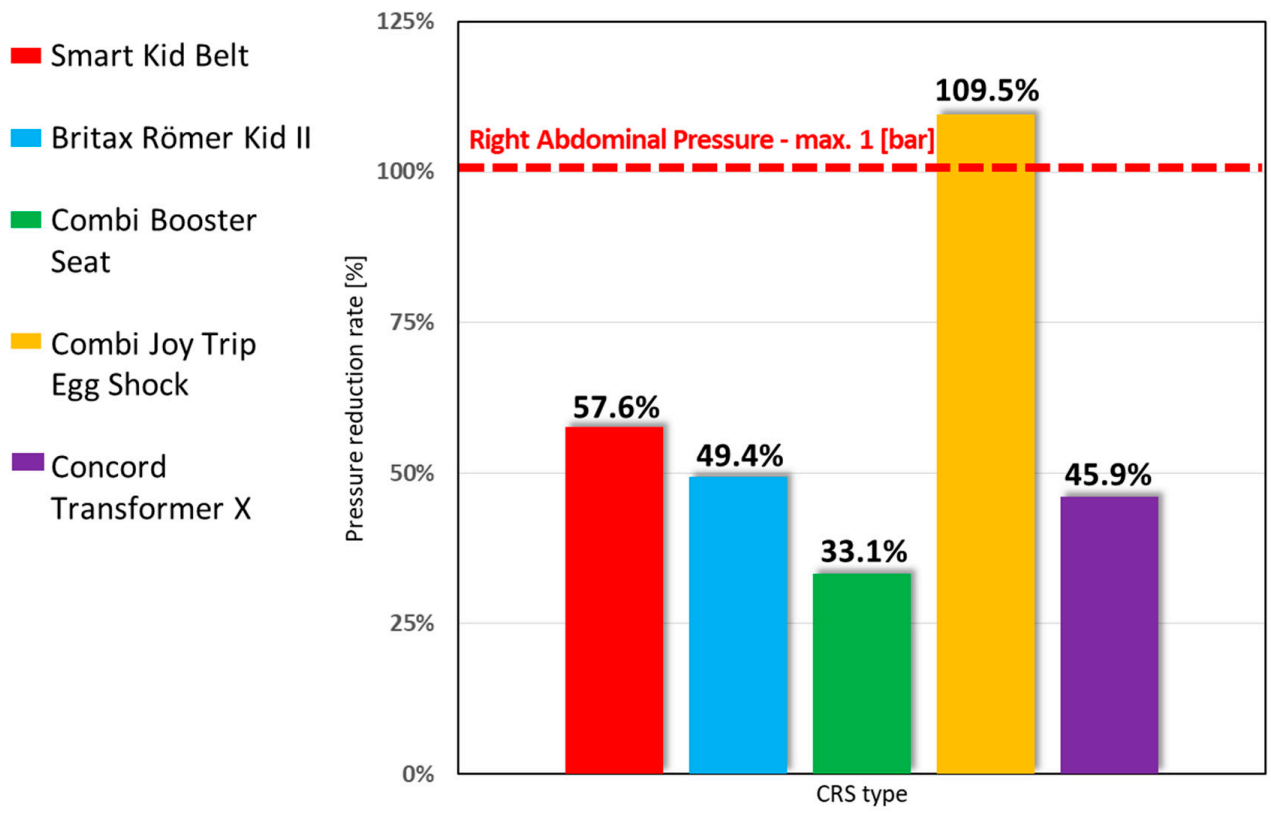

Figure 9. Right abdominal pressure for all tested devices regarding the maximum limit. Combi Booster Seat was $66.9 \%$ beneath the limit. Combi Joy Trip Egg Shock was 9.5\% over the limit, which means that it did not meet the requirements of the regulation.

Analyzing the test results (Figure 10), it can be stated that the maximum recorded values of pressure in the left abdominal segment are:

- for the Smart Kid Belt: 0.39 bar after $81.7 \mathrm{~ms}$ which is $38.9 \%$ of the limit,

- for the Britax Römer Kid II: 0.22 bar after 84.3 ms, which is $22.3 \%$ of the limit,

- for the Combi Booster Seat: 0.19 bar after $85 \mathrm{~ms}$, which is $18.6 \%$ of the limit,

- for the Combi Joy Trip Egg Shock: 0.35 bar after $85.5 \mathrm{~ms}$, which is $34.7 \%$ of the limit,

- for the Concord Transformer X: 0.2 bar after $99 \mathrm{~ms}$, which is $20.2 \%$ of the limit.

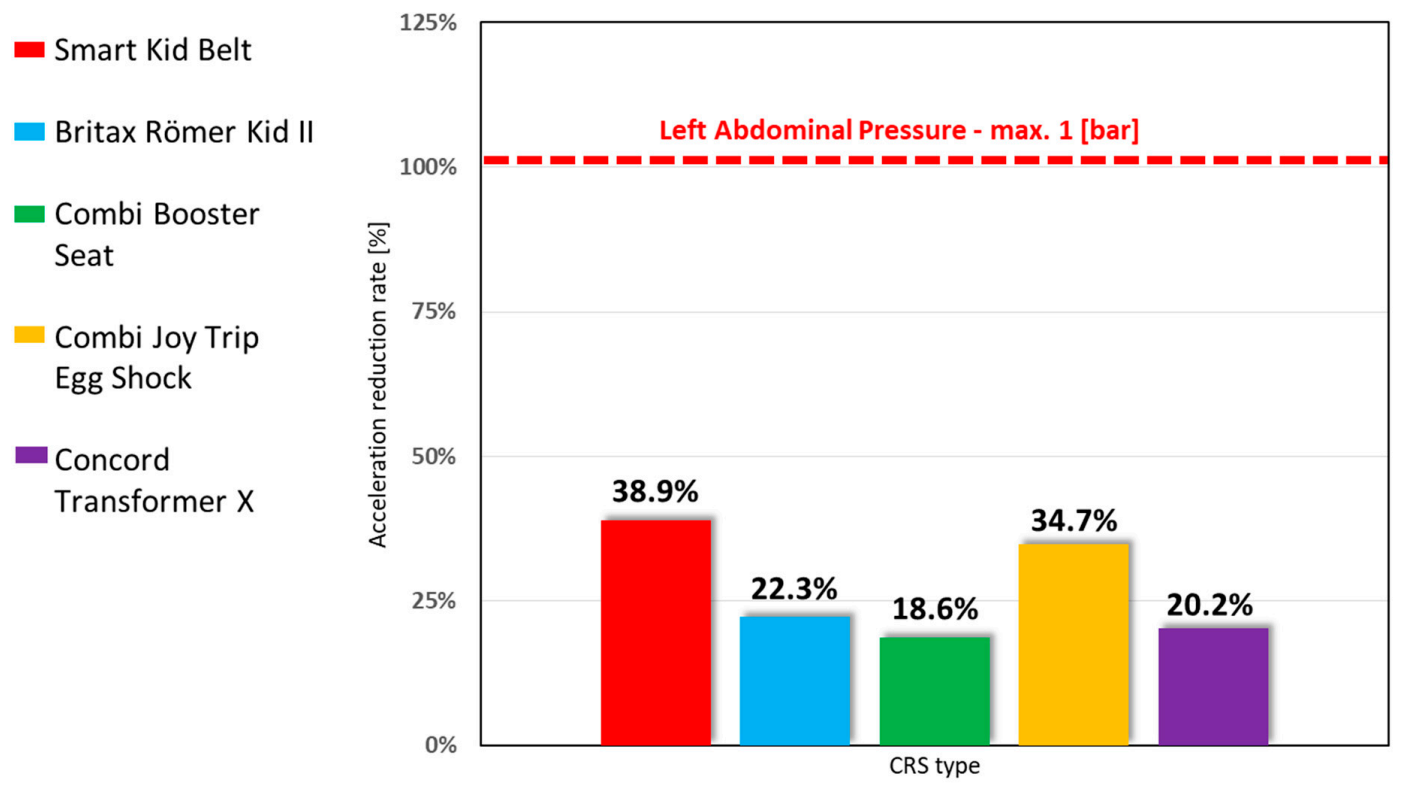

Figure 10. Left abdominal pressure for all tested devices regarding the maximum limit. All of the devices were more than $60 \%$ less than the pointed limit in the Regulation. 
The recorded values of right abdominal pressure for individual restraint systems are:

- $\quad$ for the Smart Kid Belt: 0.58 bar after $79.7 \mathrm{~ms}$ which is $57.6 \%$ of the limit.

- for the Britax Römer Kid II: 0.49 bar after 89.6 ms, which is $49.4 \%$ of the limit,

- for the Combi Booster Seat: 0.33 bar after $102.6 \mathrm{~ms}$, which is $33.1 \%$ of the limit,

- for the Combi Joy Trip Egg Shock: 1.1 bar after $85.2 \mathrm{~ms}$, which is $109.5 \%$ of the limit,

- for the Concord Transformer X: 0.46 bar after $88.1 \mathrm{~ms}$, which is $45.9 \%$ of the limit.

\section{Discussion}

The Child Restraint Systems legal regulation currently imposes very high requirements for meeting certain safety criteria on the device manufacturers. The significant growth of the professional measurement devices has enabled the investigation of a new type of children dummies with an increased number of sensors located in different parts of their bodies.

Analyzing the test results, it can be seen that the safety criteria pointed in No. 129 UN/ECE regulation was met for almost all the restraint devices tested (except for abdominal pressure in one of the tested solutions-9.5\% over the limit ). However, the analysis of recorded data and individual values of physical quantities showed significant differences between each solution. As an example of where the parameters significantly differ is the Right Abdominal Pressure, in which the differences range between each CRS are 7\% (Concord Transformer X - Britax Romer Kid II) even to 70\% (Combi Booster Seat - Combi Joy Trip Egg Shock). The number of dynamic loads is influenced by the number of each device design solutions. The different parameter values for each device might be connected with the different initial positions of the dummy, the stiffness characteristics of the element on which the child is placed, and the solution of the seat belt guidance configuration characteristics. The research results clearly show that the issue of the safety of children's transportation in vehicles requires further research and development to determine the correlation between design features of the restraint system and the registered physical parameters. The conclusion is that sthere is no one perfectly restraining device because of its design - each CRS is built differently, which causes different protection ranges of the sensitive point on the child's body determined, for example, Smart Kid Belt is marked by the highest results in safety parameters, with HPC-25.5\% and Head Resultant Acceleration-61\%, but it does not provide as good protection as the other CRSs for the right and left abdominal $-57.6 \%$ and $38.9 \%$ (the worst one of all others). The best protection of the abdominal is provided by Combi Booster Seat $-18.6 \%$ (left side) which is $81.4 \%$ beneath the limit and $33.1 \%$ (right side).

Advances in computer technology have provided the opportunity to develop effective and reliable numerical computational tools that can be used for Child Restraint Systems design. The next stage of research could be connected with the finite element methods for the creation of a child's numerical model. That type of numerical model could contain all the basic phenomena relevant to the simulation of the collision process, including mapping the child's behavior during an accident. The numerical model created in this way would significantly facilitate the analysis of many different aspects of the child restraint systems to increase safety criteria values in that type of device.

All the Child Restraint Systems tested were approved according to ECE Regulation No. 44., which means that the manufacturer met the strict conditions regarding the repeatability of the results of all the manufactured devices. The holder of the approval will be obliged to carry out continuous quality control of his manufacturing process on a statistical basis and by sampling. The control must meet the following requirements:

- in normal mode, 0.02 percent means one Child Restraint System taken from every 5000 manufactured;

- in strengthened mode, 0.05 percent means one CRS taken from every 2000 manufactured.

Where a test sample fails a particular test to which it has been subjected, another further test to the same requirement shall be carried out on at least three other samples. In the case of dynamic tests, 
if one of the latter fails, the production is considered to be non-conforming and the frequency shall be raised to the higher one if the lower one was used and necessary steps shall be taken to re-establish the conformity of the production.

Author Contributions: Project administration, A.M.; investigation, writing—original draft preparation, J.Ł.; data curation, writing - review and editing, R.S. All authors have read and agreed to the published version of the manuscript.

Funding: This study and the studies presented in it have not received any external financing.

Acknowledgments: The study is of a scientific nature and its purpose is not to commercially use the content presented in it.

Conflicts of Interest: The authors of the publication do not report conflicts or personal dependencies that could affect the result of the study and the conclusions presented in it.

\section{References}

1. Jones, L.E.; Ziebarth, N.R. U.S. Child Safety Seat Laws: Are they Effective, and Who Complies? J. Policy Anal. Manag. 2017, 36, 584-607. [CrossRef] [PubMed]

2. Wacowska-Ślęzak, J.; Dabrowska-Loranc, M. Children safety in road transport European project EUCHIRES. J. KONES 2008, 15, 51-60.

3. Department of Violence and Injury Prevention and Disability. World report on child injury prevention; World Health Organization: Geneva, Switzerland, 2008.

4. Finn, J.W.; Wagner, J.R.; Walters, E.J.; Alexander, K.E. An integrated child safety seat cooling system-model and test. IEEE Trans. Veh. Technol. 2012, 61, 1999-2007. [CrossRef]

5. Mazurkiewicz, Ł.; Muszyński, A.; Wicher, J.; Trzaska, P. Analysis of the forces developing in the straps of the belts that restrain a child in a safety seat. Arch. Motoryz. 2015, 67, 113-126.

6. Ptak, M. Method to assess and enhance vulnerable road user safety during impact loading. Appl. Sci. 2019, 9, 1000. [CrossRef]

7. Byard, R.W.; Noblett, H. Child booster seats and lethal seat belt injury. J. Paediatr. Child Health 2004, 40, 639-641. [CrossRef] [PubMed]

8. Cao, L.; Chen, H.; Ren, X.; Ouyang, Z. Study on an integrated child safety seat. Appl. Mech. Mater. 2010, 34-35, 517-522. [CrossRef]

9. Kluczyński, J.; Śniezek, L.; Grzelak, K.; Mierzyński, J. The influence of exposure energy density on porosity and microhardness of the SLM additive manufactured elements. Materials 2018, 11, 2304. [CrossRef] [PubMed]

10. Śniezek, L.; Grzelak, K.; Torzewski, J.; Kluczyński, J. Study of the mechanical properties components made by SLM additive technology. In Proceedings of the 11th International Conference on Intelligent Technologies in Logistics and Mechatronics Systems (ITELMS), Panevezys, Lithuania, 28-29 April 2016.

11. Kluczyński,J.; Śnieżek, L.; Kravcov, A.; Grzelak, K.; Svoboda, P.; Szachogłuchowicz, I.; Franek, O.; Morozov, N.; Torzewski, J.; Kubeček, P. The Examination of Restrained Joints Created in the Process of Multi-Material FFF Additive Manufacturing Technology. Materials 2020, 13, 903. [CrossRef] [PubMed]

12. Szachogluchowicz, I.; Sniezek, L.; Hutsaylyuk, V. Low Cycle Fatigue Properties Laminate AA2519-TI6AL4V. Procedia Eng. 2015, 114, 26-33. [CrossRef]

13. Szachogluchowicz, I.; Sniezek, L.; Sulym, H.; Gloc, M. Testing and verification modeling of wave-shape formation under explosion welding to laminate AA 2519-Ti6Al4V. Procedia Struct. Integr. 2016, 2, 2375-2380. [CrossRef]

14. Cummings, P. Association of seat belt use with death: A comparison of estimates based on data from police and estimates based on data from trained crash investigators. Inj. Prev. 2002, 8, 338-341. [CrossRef] [PubMed] 
15. Viklund, Å.; Björnstig, J.; Larsson, M.; Björnstig, U. Car Crash Fatalities Associated With Fire in Sweden. Traffic Inj. Prev. 2013, 14, 823-827. [CrossRef] [PubMed]

16. UN/ECE Status Document TRANS/WP.29/343. Available online: http://www.unece.org/trans/main/wp29/ wp29wgs/wp29gen/wp29fdocstts.html (accessed on 30 October 2019). 